\title{
Ankle-Worn Sensor Sleeve to increase walking motivation
}

\author{
Minatsu Sugimoto $\cdot$ Hiroo Iwata ${ }^{1,2} \cdot$ Hiroya Igarashi $^{1,3}$
}

Received: 29 September 2021 / Accepted: 21 January 2022

(c) The Author(s) 2022

\begin{abstract}
In this study, we propose the Ankle-Worn Sensor Sleeve to help people maintain their health. Furthermore, our approach uses this sensor sleeve to improve walking motivation by making the walking motion more sensible. In this research, we pursue the design of a wearable device that users can wear as a "shoe accessory," with the aim of promoting people's walking motivation. This device is ankle-worn and generates electricity using the physical flexion and extension of the ankle, detects and acquires the amount of electricity generated, and uses the resulting power to produce sound and light feedback while walking. The Sleeve is designed to support health problems, such as locomotive syndrome and dementia, which are caused by physical inactivity. This article presents the results of a questionnaire survey conducted on 172 people who experienced or observed the device during exhibitions. The results reveal that this device increased people's interest and motivation to walk, including those who did not like to walk.
\end{abstract}

Keywords Ankle-Worn Sensor Sleeve $\cdot$ Walking motivation $\cdot$ Electricity generation from walking $\cdot$ Wearable device

\section{Introduction}

Today, the progressively dwindling motivation to walk is a major social challenge. Therefore, the number of steps taken worldwide has decreased, especially post-COVID-19 (Tison et al. 2020). Additionally, studies have reported a recent trend of remote work, the associated decrease in walking time (Huntley 2021), and a significant reduction in travel time (Borkowski et al. 2021).

Lack of physical activity, including walking, affects people's health at all times, not just during epidemics and pandemics. Physical inactivity increases the risk of many adverse health conditions, including major

Minatsu Sugimoto

m_sugimoto@vrlab.esys.tsukuba.ac.jp

Hiroo Iwata

iwata@kz.tsukuba.ac.jp

Hiroya Igarashi

igarashi.hiroya.fw@u.tsukuba.ac.jp

1 School of Integrative and Global Majors, University of Tsukuba, Tsukuba, Japan

2 Faculty of Engineering, Information and Systems, University of Tsukuba, Tsukuba, Japan

3 Specially Appointed Professor, University of Tsukuba, Tsukuba, Japan non-communicable diseases, and reduces life expectancy (Morris and Hardman 1997; Lee et al. 2012).

Although exercise is an excellent, and inexpensive, method to maintain good health, lack of motivation results in physical inactivity (Baldi et al. 2020), and motivating people to engage in physical activities is a massive challenge. However, walking is an exercise that is generally easy to perform (Siegel et al. 1995; Owen et al. 2004). Although it is considered a light or moderate exercise, but even that is beneficial for health (Morris and Hardman 1997). People who do not maintain or improve their walking ability develop musculoskeletal diseases. This is known as locomotive syndrome, which necessitates nursing care (Nakamura 2011). A previous study showed that walking effectively reduces the risk of developing dementia (Tomata et al. 2017). Additionally, increase in walking time means increase in physical activity, which improves health. For example, a study on habitual physical activity, including walking, and the health of older adults (Aoyagi and Shephard 2010) showed a significant association between health status, average steps per day, and average effort per day.

Loss of motivation to walk results in long-term health problems, damages individual well-being, and poses challenges both socially and economically in terms of increased medical and care costs. Given these issues, the practical 
application of technologies that encourage people to walk more will significantly impact both society and economy.

To solve this social issue, we propose to arouse people's interest in walking. Therefore, we focused on simplifying for people the movement of walking in a sensory manner and making pedestrians happy to walk by offering the experience of generating electricity by walking. We developed the Ankle-Worn Sensor Sleeve to provide this experience of power generation through walking. It is an ankle-worn sensor sheet that does not require a battery and can be worn as an accessory on the user's shoes. It generates electricity when the user walks and detects the walking motion based on the amount of electricity generated. The device makes a sound or glows in response to the detected walking motion, making it possible to understand it more sensitively. The goal was to increase the motivation to walk.

To verify its social acceptance, we tested it in an art exhibition. We offered people the experience of the Sleeve and requested them to complete a questionnaire afterwards. Behavior of those who experienced the Sleeve and their responses in the questionnaire revealed increased motivation to walk.

\section{Basic concept of the Ankle-Worn Sensor Sleeve}

The Ankle-Worn Sensor Sleeve is a device that can be worn as a "shoe accessory" and allows users to experience "power generation when walking." This device includes elements of the concept of device art and the concept of human function extension.

\subsection{Shoe accessories and interaction inspired by device art}

The term "device art" refers to interactive works employing mechatronic and material technologies to turn technology into art in the form of a display (Iwata 2012). Device art is an important technology because it focuses on the user experience. To develop technology that makes people want to walk more, the technology has to be practical so that people easily accept and adopt it. Therefore, to make it easier to wear, the Sleeve was designed as a "shoe accessory." This is in line with the concept of device art, which aims to "turn technology into art in a form that shows it." This concept has two perspectives: one that emphasizes playfulness, because "the playfulness of experiencing a work of art is an important essence of device art," and the other that assumes commercialization, because "in device art, commercialization occupies an important position in the creation of a work of art" (Iwata 2012).
The Sleeve incorporates the "interaction as the content" perspective as a means of motivating people to walk. The source of the interaction is the bending and stretching of the legs during walking, which is the act of walking itself. Therefore, by creating a new interaction experience from this movement, we aimed to make pedestrians more interested in walking.

We also created the experience of generating electricity through walking. We found this idea from the category titled "physical phenomena generated by human actions," under the classification of device art in terms of devices and their use; it states: "A device contains a mechanism that generates a certain physical phenomenon, and the act of a person operating the device generates the physical phenomenon" (Iwata 2012).

\subsection{The hypothesis of functional expansion and the "experience of power generation" leading to increased walking motivation}

This study aims to increase people's motivation to walk by providing the "experience of walking and power generation." The author's hypothesis of the expansion of human functions is the premise of the idea that the experience of walking and power generation will increase people's walking motivation. The hypothesis is that "walking leads to power generation"- $\mathrm{a}$ function not naturally associated with human beings - and that practicing this function is "an interesting way to add productivity to one's daily activities." Additionally, there is the joy of performing more activities. Therefore, people will find it interesting and pleasurable to extend their functions. The central idea of the technology acceptance model (TAM) is that a person's behavioral intention (BI) to use a "system" (a new hardware or software) is primarily based on its utility and ease of use (EOU) and the pursuit of EOU leads to enjoyment (Bruner and Kumar 2005). For example, in the Sleeve, electricity generation is added to the function of human movement.

Another reason for choosing the function of electricity generation is the compatibility between walking motion and power generation. Based on an idea drawn from the above-mentioned "physical phenomena generated by human actions" category of device art (Iwata 2012), I considered the possibility of converting the bending and stretching motion of the legs into a physical phenomenon. We considered it essential to realize an interaction that conveys the walking motion to the walker more sensitively and clearly. To achieve this, it was necessary to detect the timing of walking and have an output that matched the timing. Additionally, to realize the detection and output, it was necessary to supply power to the device. Based on these ideas, we developed the concept of walking power generation. 
Another advantage of making the power generation system itself the center of the interaction mechanism is that it does not require a battery. Therefore, elimination of the battery makes the device smaller, saves labor, and negates battery replacement. This miniaturization and labor-saving are essential for making the technology more acceptable to users and emphasize the playfulness of the device art.

\subsection{Reasons for designing it as an ankle wear}

The Sleeve is a wearable device worn around the ankle, though several body parts can generate electricity during walking. It is attached to the tibia (Schott 1993) and the back of the foot, where the shoes are worn. This ingenious mounting location reduces the sense of constraints caused by mounting and minimizes the feeling of the device being on the body. The reasons for the suitability of the ankle as the device's attachment point are the same as of a study that explored the body's approach point for tactile presentation to control a person's walking rhythm (Baldi et al. 2018). In this study, subjects preferred the ankle position for the device in terms of wearability, comfort, and ease of performing the task.

Through this, we aim to improve the playfulness of the device and increase its EOU. Additionally, the device's shape should not interfere with body movements, and the tool should not feel constricted on the feet. Finally, we aim to create a state in which users can be active, as if they are not wearing the device.

\section{Related work}

\subsection{Market applications to support walking promotion}

To promote exercise, mainly walking, already there are devices in the market, such as the Apple Watch's workout app and Fitbit, which can measure and record various activities, including walking, and set the level of achievement.

Although they measure the gait (Fuller et al. 2021), they only perform sensing and do not have any function of actuation, such as transferring sensations directly to the body to promote walking or facilitating the walking motion by providing external stimulus or force to the body. Additionally, the battery requires recharging and replacement.

In this study, we sense the walking motion. The system presents stimuli, such as sound, light, and vibration, in conjunction with the sensed walking motion of the user. In this way, the user's walking motion becomes sensory information that is directly transmitted to the user. The main difference between the Sleeve and these apps is that it has the function of actuation.

\subsection{Related research on the relationship between sensory alteration/sensory addition and behavioral change/motivation enhancement}

Several studies have aimed to change people's walking behavior and increase their walking motivation by altering existing sensations or adding new sensations while walking. In one such study that aimed to increase walking motivation by altering the sensation felt during walking, a person's footsteps were detected and the walking sound was changed to change the way the person felt his or her weight, thereby increasing the motivation for physical activity (TajaduraJiménez et al. 2015). Furthermore, research on changing the walking motion by adding a new sensation during walking includes a study in which the walking tempo changes using the vibration transmitted from a device attached to the ankle, such as a metronome (Paolocci et al. 2018). Another study aimed to increase the walking motivation of users by giving vibration stimuli to their toenails while walking to make them feel the texture of the ground on their feet (Sakai et al. 2018).

These studies suggest that altering the sensations felt while walking or adding new sensations can change walking behavior and lead to increased motivation to walk. However, these studies required special shoes for the device, largescale equipment including external power supply and batteries, which required frequent recharging or replacement. This suggests possible issues related to usability in daily use.

The novelty of this research lies in: (a) the fact that users can wear the device over their favorite shoes, and (b) the interaction to create sensation without an external power supply or battery while aiming to change walking behavior and increase walking motivation.

\subsection{Related research on the timing of the presentation of added sensations and on added senses (sound, light, and vibration)}

To make the sensation of walking motion easier to feel, changes in sensation while walking must be swiftly conveyed to users. For example, with changes in the walking timing or the timing of each step, the added sensation must change accordingly. This is in line with another study (Tajadura-Jiménez et al. 2015) that detected footsteps.

Additionally, there was a study that aimed to promote walking by providing visual feedback when walking (Thikey et al. 2012); a study that promoted walking by talking to people when walking (Karageorghis and Terry 1997); and a study that aimed to motivate people to walk by massaging their feet (Manabe et al. 2007). However, these systems necessitate an external power supply or personnel, and 
cannot be used efficiently during daily walking. Therefore, this study proposes a system for tactile, auditory, and visual senses that change and add to the walking motion, based on previous studies that used visual, auditory, and tactile approaches to promote walking and movement.

\subsection{Related research and problem of power generation mechanisms related to walking}

There have been studies on the incorporation of electromagnetic coils (Ylli et al. 2014) and piezoelectric sheets (Zhao and You 2014) into shoes to generate electricity. These studies aimed only to generate electricity using the walking motion, and the detection of that motion from the generated electricity was not assumed; so, it may be challenging to provide feedback to users according to their walking motion. The mechanism of these devices is such that the direction of movement of the coil is constant and no pressure is applied during the swing period, making it difficult to detect walking motion from the amount of power generated. Additionally, devices with electromagnetic coils and other power generation devices require special shoes. The inability to use one's preferred shoes will make it difficult for users to choose and use such devices in their daily life activities, which will hinder the spread of the device. A study on generation of electricity by installing a gear-type generator next to the knee (Donelan et al. 2008) revealed that heavy and oversized devices obstruct walking. As described above, previous related research had several limitations, such as unwieldly objects inhibiting walking or there being periods of undetected motion.

However, this study has three novelties. First, it uses a "shoe accessory" that can be worn over the user's favorite pair of shoes. Second, the device generates electricity through the walking motion and detects the walking motion based on the electricity generated. Third, the power generation mechanism does not interfere with walking because the tightness and weight of the device were taken into consideration when designing its shape.

\section{System design}

Based on these previous studies and the basic concept of the Sleeve, the following six design guidelines were obtained to design a wearable device - a "shoe accessory"- to promote walking motivation.

Design guidelines:

1. A lightweight, non-restrictive "shoe accessory."

2. Power generation with minimal force.

3. Battery-free power generation mechanism to reduce device size.
4. Detection of walking motion based on the power generated.

5. Production of sound and light to experience power generation.

6. A commercial design for the device.

To realize guideline (1), we devised a lightweight belt that fits around the ankle, is easy to adjust for tightness, and easy to wear and remove.

To realize guidelines (2) and (3), the Sleeve employs a power generation mechanism using a vibration-based generating element sheet driven by a light force. Additionally, we devised a way of connecting the vibration-based generating element sheets and combined them vertically (Fig. 1), which makes it easier to bend the ankle.

The Sleeve also performs the function of "detecting walking motion from the amount of power generated,"- - design guideline (4). In this way, it can be used as a battery-free walking sensor by estimating the walking posture based on the amount of power generated from the ankle joint flexion and extension movements that change the angle in conjunction with the walking motion.

Additionally, it will "present sound and light using the generated power as a means of experiencing power generation," as stated in design guideline (5).

Finally, it is essential to "consider the design of the device with commercialization in mind," as states design guideline (6).

Based on the design guidelines created from the basic concept, in the Sleeve a device that does not interfere with walking is realized (Fig. 2).

\section{Implementation}

The Sleeve was developed based on this system design. We used a belt with tape to make it easy to wear and remove the device. Additionally, the connection between the belt and the vibration-generating element sheet made with tape

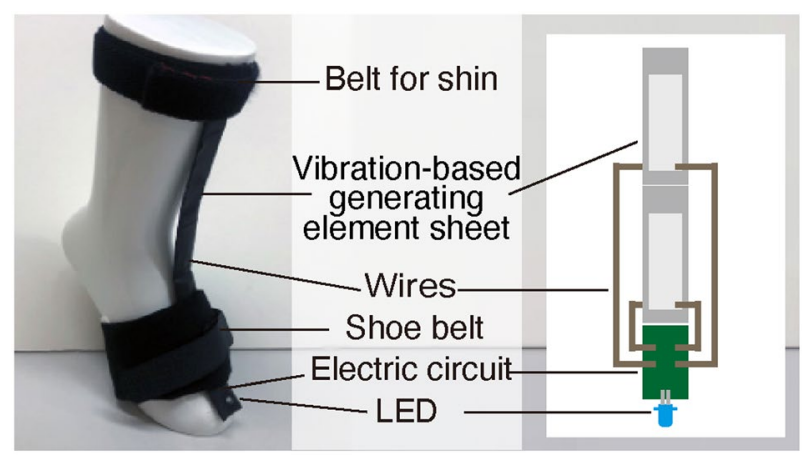

Fig. 1 System design of Ankle-Worn Sensor Sleeve, LED version 


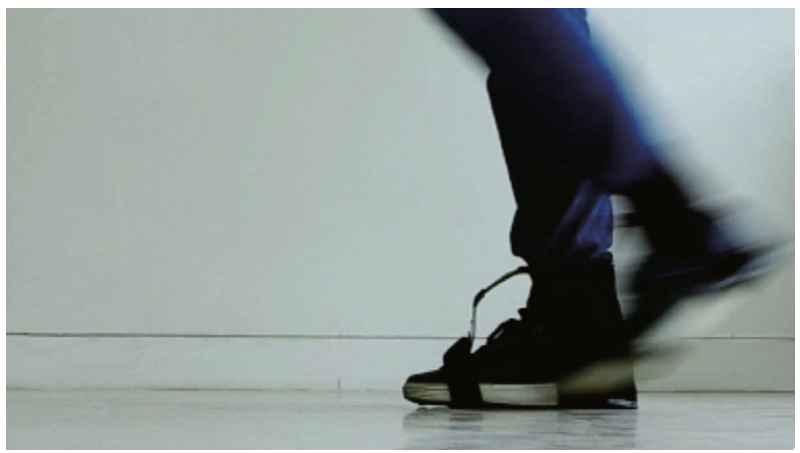

Fig. 2 Wearing the Ankle-Worn Sensor Sleeve while walking

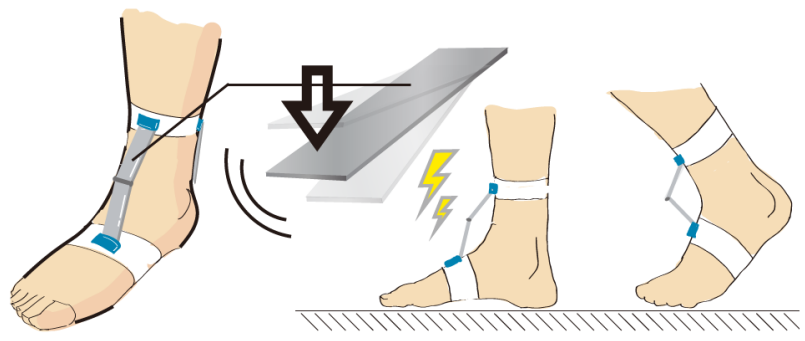

Fig. 3 Ankle movement based electricity generation mechanism

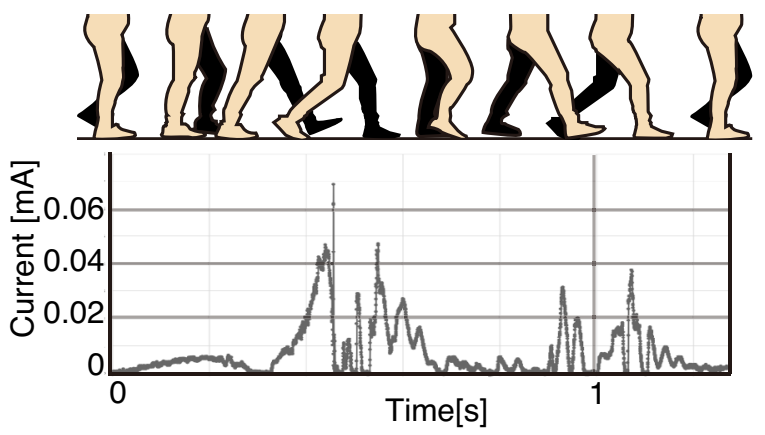

Fig. 4 Power generation current per step and walking cycle

can be easily attached and removed repeatedly. Each sheet of the vibration-generating element (THRIVE, K7520BS3) used was small in size $(75 \mathrm{~mm} \times 20 \mathrm{~mm})$, its characteristics were low, and it bent easily. Using a structure that does not interfere with walking, the vibration and bending mechanism reduce the force applied to the leg because of power generation and the sense of constraint when wearing it. We connected two sheets of this vibration-generating element per leg to create an electricity generation mechanism (Fig. 3). We also verified whether this mechanism could generate electricity. We found that $0.04 \mathrm{~mA}(0.04 \mathrm{~V}, 0.0016 \mathrm{~mW})$ was generated per sheet per step and that power was wellgenerated at the first bend (Fig. 4).

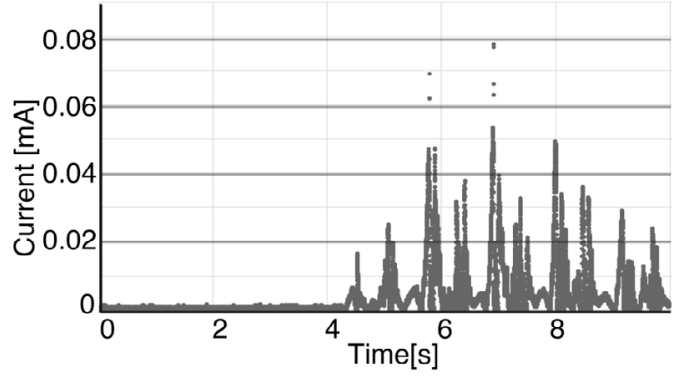

Fig. 5 Current generated from the start of walking up to five steps

Additionally, when we measured the continuous walking motion, it was observed that the ankle generated $2 \mathrm{MW}$ per step: $1 \mathrm{MW}$ when flexed; $1 \mathrm{MW}$ when extended (Fig. 5). This result suggests that the mechanism generates power and that the amount of power generated is regular. Moreover, it indicates that this mechanism can be used as a sensor sheet for detecting the walking motion. Furthermore, it is different from conventional sensors that detect ankle flexion and extension. Finally, it does not require a battery because of the structure of the vibration-generating element sheet, so it can be used continuously without recharging.

Using the power generated through this mechanism, we developed an ankle-mounted sensor sheet that produces a sound, vibrates, or lights up an LED in response to walking movements. Furthermore, using this ankle-mounted sensor sheet as an oscillator switch, we developed a device that provides vibration feedback based on the timing of walking (Fig. 6) (Sugimoto et al. 2019). Additionally, we developed a device that provides sound feedback when users walk, and another device that provides visual feedback when users walk. In these devices, the generated power is used as a switch and power for feedback, so the amount of power generated changes when the use of the ankle joint or walking motion changes-for example, the feedback changes when walking fast or jumping.

\section{Design study}

We pursued the design of a device that could be worn as a "shoe accessory." The developed Ankle-Worn Sensor Sleeve was shown at seven different exhibitions (Table 1). At each exhibition, we showed the Sleeve with sound feedback, the one with visual feedback, and a concept model. At these exhibitions, we conducted questionnaire surveys and interviews with a total of 172 visitors. Consequently, improvements were made to the design of the Sleeve, and through those improvements, we confirmed the concept of the Sleeve. 
Table 1 Exhibition and participants

\begin{tabular}{llllll}
\hline & Exhibition & Event dates & Place & Figure & Participant \\
\hline 1 & Ars Electronica Festival 2017 & September 7-11, 2017 & Austria & Figure 7a & Questionnaire: 30 people \\
2 & Speculum Artium 2017 & September 14-16, 2017 & Slovenia & Figure 7a & Questionnaire: 10 People \\
3 & Tsukuba Media Art Festival 2018 & July 28-August 5, 2018 & Japan & Figure 7b & Experience: 10 people \\
4 & Asia Haptics 2018 & November 14-16, 2018 & Korea & Figure 6 & - \\
5 & VR Undoukai 2020 & February 2, 2020 & Japan & Figure 7c & - \\
6 & School of The Future 2020 & February 20-24, 2020 & Japan & Figure 7c & Questionnaire: 52 people \\
7 & Tsukuba Media Art Festival 2021 & July 30-August 5, 2021 & Japan & Figure 7d & Experience and Ques- \\
& & & & & tionnaire: 70 people \\
\hline
\end{tabular}

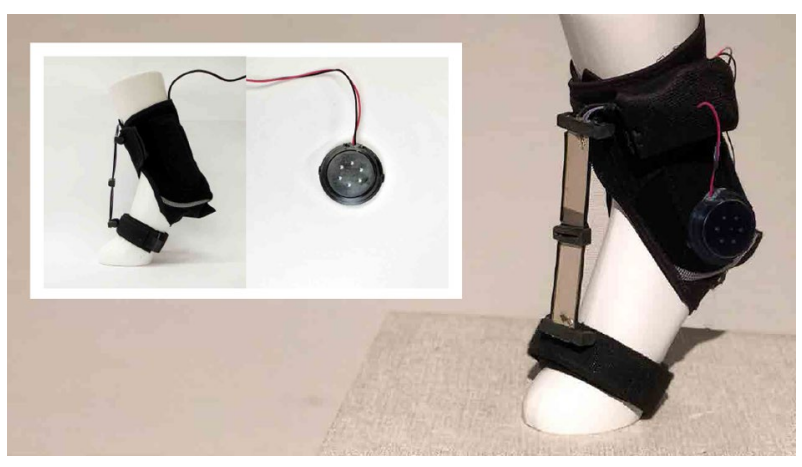

Fig. 6 Vibration feedback system

The feedback received at these exhibitions was used to improve the device-the improvement process is shown in Fig. 7.

At the Ars Electronica Festival 2017 and the Speculum Artium 2017, we exhibited an Ankle-Worn Sensor Sleeve with sound feedback when walking (Fig. 7a). The visitors shared that they had high expectations from the device but the exposed wiring seemed too fragile for daily use. A high expectation from the device was also suggested by the results of a questionnaire survey conducted on 40 visitors. In this survey, 13 people answered "Yes" to the question, "Are you satisfied with your current amount of exercise?" (Table 2). This suggests that many people are dissatisfied with their current state of walking. When asked, "How many minutes do you walk a day?" and "How many minutes do you think you should walk a day?," 21 respondents were not satisfied with their current amount of walking, of which 17 said they should walk for a longer time and four did not answer this question. Based on the responses of those 17 visitors, it was found that the difference between the time people thought they should spend walking, and the time they actually spent walking, was about $53 \mathrm{~min}$ on average. These responses suggest that many people desire to walk more than they currently do. This result also shows that the concept of the Sleeve is suitable for the required promotion of walking.
Based on the feedback received at the Ars Electronica Festival 2017 and the Speculum Artium 2017, at the Tsukuba Media Art Festival 2018, we exhibited a device that can produce various sounds. In response to the feedback that "the exposed wiring of the device seems to be fragile and not suitable for daily use," we changed the device's design by integrating the wiring as much as possible into the belt (Fig. 7b). Feedback from visitors to this exhibition included, "The bare steel sheet gives the impression of a prototype, and I cannot imagine using this device in daily life," and "It does not look like it can be used on rainy days."

In response to the feedback received at the three exhibitions, especially regarding the appearance of the device and its impressions, we improved the appearance of the device prior to exhibiting it at the School of The Future 2020. We developed a concept model to study its appearance (Fig. 7c) and asked 52 visitors whether they liked the appearance of the devices: $60 \%$ of them responded with "very much" and "somewhat" (Table 3 ). We also asked them whether they would actually like to use the devices on display. From those who answered, "very much," reasons were sought in the free answer column. The reason for the "somewhat agree" response was, "The vertical lines seem to have a leg-lengthening effect. There is a possibility in the future." For those who answered, "I do not know," the most common reason was that "it would be good if it were not in my luggage." These responses suggested that the shape of the device exhibited at the School of The Future 2020 was generally accepted.

At the Tsukuba Media Art Festival 2021, we used the same shape of the device, but made it less conspicuous, as requested by the visitors, by coloring it black. The design was improved to respond to visual feedback by lighting up LEDs attached to the device (Fig. 7d).

We improved the device based on the feedback from the public. In this way, we confirmed whether the concept of the device would be accepted by the public or not, and pursued the design of a device wearable as a "shoe accessory." 

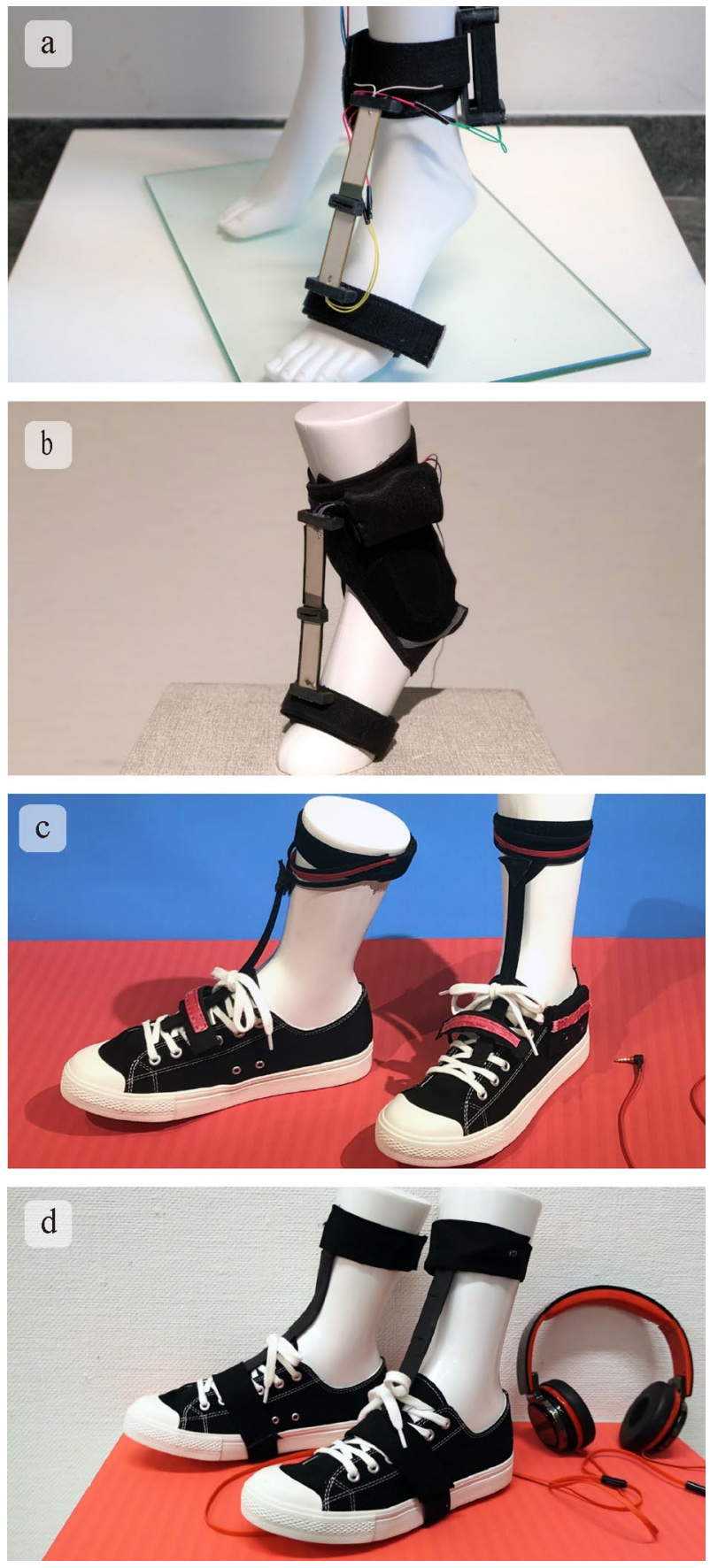

Fig. 7 Improvements in the Ankle-Worn Sensor Sleeve design

\section{Evaluation}

At the exhibitions, we conducted questionnaire surveys and collected feedback from visitors after providing them a hands-on experience with the device to evaluate whether the Sleeve could make people interested in walking and motivate them for the same.

At the Tsukuba Media Art Festival 2018, visitors experienced the Sleeve (Fig. 7b). We explained to them that the Sleeve generates electricity through the walking motion, produces a sound when the wearer walks, and the sound changes depending on the gait. The visitors who tried the device were observed walking in a circle in front of the exhibition area and jumping several times (Table 4-1), which suggested their interest in the sound produced.

Furthermore, when we later interviewed them about the device, we received such comments as the following: "It is interesting that the sound changes with the movement. I feel like I am being induced to move hard. I want to find the sound, so I stomp my feet hard and do other things, but I cannot figure out the cause, and it is bothering me" (Table 42). These observations and interviews revealed that the participants found the experience exciting and wanted to walk more to hear the sound.

At the Tsukuba Media Art Festival 2021 exhibition, the Sleeve (Fig. 7d) was tried by 70 visitors, who also completed the questionnaire. First, the questionnaire asked, "Do you like to walk?" Eight people answered, "No." After they had tried the device, the questionnaire asked, "Have you become more interested in walking after using the device?" It was confirmed that interest in walking had increased for seven of these eight participants (Table 5).

\section{General discussion}

\subsection{Findings obtained through the exhibition and design guidelines for the shape of the device}

Through the exhibitions, we obtained many findings regarding the influence of the device's design on the willingness to walk (Table 6). As for the motivation to walk, the results of the surveys at the Ars Electronica Festival 2017 and

Table 2 Forty survey responses at the Ars Electronica Festival 2017 and the Speculum Artium 2017

\begin{tabular}{llllll}
\hline Question $(n=40)$ & Answer & $n$ & Question $(n=21)$ & Answer & $n$ \\
\hline Are you satisfied with your current amount of exercise? & Yes & 13 & & & \\
& No & 21 & $\begin{array}{c}\text { Average of responses to how much more } \\
\text { walking I should do than I am doing now }\end{array}$ & 53 min & Not answered \\
& & & & \\
& Other & 6 & & \\
\hline
\end{tabular}


Table 3 "Do you like the look of the device?" questionnaire results

\begin{tabular}{llll}
\hline Question & $\begin{array}{l}\text { Do you like the look of the } \\
\text { device? }\end{array}$ & $n$ & $\%$ \\
\hline Answer & Very much & 5 & 10 \\
& A little & 26 & 50 \\
& Neither & 7 & 13 \\
Not much & 11 & 21 \\
& Not at all & 1 & 2 \\
& Not answer & 2 & 4 \\
\hline
\end{tabular}

Speculum Artium 2017 suggested that many people wanted to walk more than they currently did. Based on the impressions obtained from the Sleeve experience and the results of the interviews at the Tsukuba Media Art Festival 2018, it is clear that there is a need to promote walking-which is the direction of the Sleeve concept. The crossover of "the experience of generating electricity by walking" and "the experience of changing the sound depending on the difference in the way you walk" (the difference in the amount of electricity generated), which is a novel experience, is believed to have produced the behavior of repeatedly walking on the

Table 4 Behavior and comments during the Ankle-Worn Sensor Sleeve experience

\begin{tabular}{|c|c|c|}
\hline \multirow[t]{3}{*}{1} & \multicolumn{2}{|c|}{ Changes in behavior observed during the exhibition experience } \\
\hline & Action 1 & Walking in a circle in front of the exhibition area \\
\hline & Action 2 & Jumping several times in front of the exhibition area \\
\hline \multirow[t]{4}{*}{2} & \multicolumn{2}{|c|}{ Comments from the interview survey during the exhibition } \\
\hline & Comment 1 & "It's interesting that the sound changes with the movement" \\
\hline & Comment 2 & "If the sound is made when your feet touch the ground, it would emphasize the feeling of walking" \\
\hline & Comment 3 & $\begin{array}{l}\text { "I feel like I'm being induced to move hard. I want to find the sound, so I stomp my feet hard and } \\
\text { do other things, but I can't figure out the cause and it's bothering me" }\end{array}$ \\
\hline
\end{tabular}

Table 5 Results of the beforeand after-use survey on eight people who do not like to walk

\begin{tabular}{|c|c|c|c|}
\hline Question & $\begin{array}{l}\text { Q1_Do you } \\
\text { like to walk? }\end{array}$ & $\begin{array}{l}\text { Q2_Do you feel like walking } \\
\text { more after using the device? }\end{array}$ & $\begin{array}{l}\text { Q3_Have you become more inter- } \\
\text { ested in walking after using the } \\
\text { device? }\end{array}$ \\
\hline Answer choice & $\begin{array}{l}1-\mathrm{Yes} \\
2-\mathrm{No}\end{array}$ & $\begin{array}{l}\text { 1-Not at all } \\
\text { 2-Not much } \\
\text { 3-Neither } \\
\text { 4-A little } \\
\text { 5-Very much }\end{array}$ & $\begin{array}{l}\text { 1-Much less } \\
\text { 2-Somewhat decreased } \\
\text { 3-Neither } \\
\text { 4-Somewhat increased } \\
\text { 5-Increased a lot }\end{array}$ \\
\hline Experiencer & $12-\mathrm{No}$ & 5-Very much & 5-Increased a lot \\
\hline Experiencer 2 & 2-No & 2-Not much & 3-Neither \\
\hline Experiencer 3 & $2-\mathrm{No}$ & 4-A little & 4-Somewhat increased \\
\hline Experiencer 4 & 2-No & 4-A little & 5-Increased a lot \\
\hline Experiencer 5 & 2-No & 4-A little & 4-Somewhat increased \\
\hline Experiencer 6 & 2-No & 4-A little & 4-Somewhat increased \\
\hline Experiencer 7 & 2-No & 4-A little & 4-Somewhat increased \\
\hline Experiencer 8 & $2-\mathrm{No}$ & 4-A little & 4-Somewhat increased \\
\hline
\end{tabular}

Table 6 Findings from each exhibition

\begin{tabular}{|c|c|c|c|}
\hline Exhibition & Study & $n$ & Obtained findings \\
\hline Ars Electronica Festival 2017 & Questionnaire & 40 & $\begin{array}{l}\text { Obtained findings 1: it was suggested that many people want to walk more than they } \\
\text { do now }\end{array}$ \\
\hline \multicolumn{4}{|l|}{ Speculum Artium 2017} \\
\hline Tsukuba Media Art Festival 2018 & Experience & 10 & Signs of increased motivation to walk were observed \\
\hline School of The Future 2020 & Questionnaire & 52 & The appearance and shape of the improved device are generally acceptable to people \\
\hline Tsukuba Media Art Festival 2021 & $\begin{array}{l}\text { Experience and } \\
\text { Questionnaire }\end{array}$ & 70 & $\begin{array}{l}\text { Seven of the eight respondents who "do not like to walk" reported an increased } \\
\text { willingness and interest in walking after experiencing the device }\end{array}$ \\
\hline
\end{tabular}


spot, and the comments supporting the motivation for this behavior. At the Tsukuba Media Art Festival 2021, seven out of eight participants (11\% of all participants) who had answered, "I do not like to walk" increased their motivation and interest in walking after experiencing the device. This indicates that even those who did not like to walk became interested in walking after trying the Sleeve. Additionally, more than $80 \%$ of the 62 people who answered, "I like walking" (89\% of all participants) reported an increase in the motivation and interest in walking. This shows that apart from making those people interested in walking who dislike this activity, the Sleeve experience increased the walking interest of people who liked to walk. These results were supported by the comments and observed behaviors of the general public who experienced the device-especially the fact that they walked in a circle to hear the sound. The sensitization of people toward walking using the Sleeve to generate electricity, produce sound-and change the sound with the change of gait-, and produce light, led to their interest in walking and increased their motivation to walk.

As for the social acceptance of the design, the Sleeve has been improved after each exhibition by incorporating users' feedback and suggestions. At the School of The Future 2020, where the improved Sleeve was exhibited, 60\% of the respondents answered that they liked the device's appearance.

The fact that the general public accepted the appearance and shape of the Sleeve suggests the possibility of social acceptance of its basic concept-a "shoe accessory."

This realization increases the options for developers of new devices when they are concerned about the shape of the device from the perspective of social acceptability. The conventional option is to make the device as invisible as possible, for example, by embedding it in shoes or other objects around us. However, because of this research, we believe that we can offer a new option for developers to create devices as accessories for people's conventional outfits, like "shoe accessories." Additionally, when developers create new devices as accessories, they can follow the basic concept of the Sleeve and the six design principles outlined in the system design. Furthermore, the improvement of a device by obtaining feedback from public through exhibitions, as in this research, can also serve as a possible development process for future devices.

\subsection{Characteristics of the sleeve and comparison with conventional methods}

The most distinctive feature of the Sleeve is that it is designed as a "shoe accessory" for use with commercially available shoes. Additionally, it uses a power generation mechanism driven by walking as a sensor for detecting walking motion-which is the source of the behavior-for increasing people's motivation to walk, which is in contrast to other studies that aim to promote walking or generate power for walking. The novelty and usefulness of this device lies in the fact that it does not require a battery or external power source, and that it induces people to walk more by presenting a stimulus linked to the walking behavior using the generated power.

Table 7 shows the detailed comparison of the Sleeve with works that aim to promote walking and those that generate walking power. In comparison with the study about changed footstep sound (Tajadura-Jiménez et al. 2015), the study to change the tempo of walking (Paolocci et al. 2018), and the study of toenail vibration stimulation (Sakai et al. 2018), the Sleeve has an advantage that it can be used with the user's preferred pair of shoes, and the interaction system can be executed without an external power supply or battery. In comparison with the study that aims to promote walking by providing visual feedback when walking (Thikey et al. 2012), the study to promote walking by talking to people when they walk (Karageorghis and Terry 1997), and the study of the importance of foot massage to increase motivation to walk (Manabe et al. 2007), this device is helpful in that it does not require external equipment or human support. Additionally, compared with the research on incorporating electromagnetic coils into shoes (Ylli et al. 2014), the Sleeve can be combined with the user's preferred pair of shoes. Compared with the research on generating electricity by incorporating piezoelectric sheets (Zhao and You 2014), it has a novelty in detecting walking motion and providing stimuli to promote walking. Compared with the research on generating electricity by installing a geared generator next to the knee (Donelan et al. 2008), it is different in that it promotes walking by generating electricity and has a shape and weight that do not interfere with the act of walking.

The Sleeve has each of the above differences compared to related works. As it satisfies all of the above criteria, it is considered a device that is suitable for daily use, emphasizes playfulness, is designed as a "shoe accessory" that users can readily accept, and has an effect that promotes walking.

\section{Conclusion}

In this study, we propose the Ankle-Worn Sensor Sleeve to maintain people's health. The Sleeve was conceived from the concepts of device art and human function enhancement. As an approach to the health hazards and associated personal, social, and economic challenges that result from a lack of motivation for people to walk, we proposed a device to make people more interested in walking. The Sleeve intends to increase interest and motivation in walking by enhancing the sensation of walking. The most crucial differentiating feature between this method and conventional methods is that 
Table 7 Comparison of the Ankle-Worn Sensor Sleeve with previous studies

\begin{tabular}{|c|c|c|c|c|c|c|c|c|}
\hline & $\begin{array}{l}\text { The device can be } \\
\text { used in conjunction } \\
\text { with the user's } \\
\text { favorite shoes. }\end{array}$ & $\begin{array}{l}\text { Gait behavior } \\
\text { change, behavior } \\
\text { motivation } \\
\text { enhancement }\end{array}$ & $\begin{array}{l}\text { Detection of } \\
\text { walking motion }\end{array}$ & $\begin{array}{l}\text { Actuation linked to } \\
\text { walking motion }\end{array}$ & $\begin{array}{l}\text { No need to } \\
\text { recharge the } \\
\text { battery, no need to } \\
\text { take it on and off } \\
\text { for recharging }\end{array}$ & $\begin{array}{l}\text { No need for } \\
\text { external power } \\
\text { supply or } \\
\text { equipment } \\
\text { including batterie }\end{array}$ & $\begin{array}{l}\text { Shape and weight } \\
\text { that do not interfere } \\
\text { with walking }\end{array}$ & $\begin{array}{l}\text { No need for human } \\
\text { support }\end{array}$ \\
\hline Ankle-Worn Sensor Sleeve & O & O & 0 & 0 & 0 & 0 & 0 & 0 \\
\hline Apple watch,Fitbit & & & 0 & $x$ & $x$ & 0 & 0 & 0 \\
\hline $\begin{array}{l}\text { A study to change the footstep } \\
\text { sound (Tajadura-Jiménez } \\
\text { 2015). A study to change the } \\
\text { tempo of walking (Paolocci } \\
\text { 2018). A study of toenail } \\
\text { vibration stimulation (sakai } \\
\text { 2018). }\end{array}$ & $\bigcirc$ & ○ & 0 & ○ & & $\times$ & 0 & ○ \\
\hline $\begin{array}{l}\text { A study that aims to promote } \\
\text { walking by providing visual } \\
\text { feedback when walking } \\
\text { (Thinkey 2012) }\end{array}$ & $x$ & 0 & ○ & $\bigcirc$ & $\bigcirc$ & $\times$ & & O \\
\hline $\begin{array}{l}\text { A study that aims to promote } \\
\text { walking by talking to people } \\
\text { when they walk (Karageorghis. } \\
\text { 1997) }\end{array}$ & O & 0 & & 0 & 0 & 0 & & $x$ \\
\hline $\begin{array}{l}\text { A study of foot massage to } \\
\text { increase motivation to walk } \\
\text { (Manabe 2007) }\end{array}$ & $\bigcirc$ & 0 & $\times$ & $\times$ & O & 0 & & $\times$ \\
\hline $\begin{array}{l}\text { Research on incorporating } \\
\text { electromagnetic coils into shoes } \\
\text { (Ylli2014). }\end{array}$ & $\times$ & $\times$ & $\times$ & $\times$ & 0 & 0 & 0 & 0 \\
\hline $\begin{array}{l}\text { Research on generating } \\
\text { electricity by incorporating } \\
\text { piezoelectric sheets } \\
\text { (Zhao2014). }\end{array}$ & $\bigcirc$ & $\times$ & $\times$ & $\times$ & O & 0 & 0 & 0 \\
\hline $\begin{array}{l}\text { Research on generating } \\
\text { electricity by installing a geared } \\
\text { generator next to the knee } \\
\text { (Donelan 2008) }\end{array}$ & $\bigcirc$ & $\times$ & & $\times$ & ○ & $\bigcirc$ & $\times$ & O \\
\hline
\end{tabular}

we pursued the design of a "shoe accessory." Additionally, the design emphasizes the playfulness of the device. This research aims to make people more interested in walking to keep them healthy, and provide them with the experience of generating power through walking. For this, we developed a sensor sheet that generates electricity using the movement of the ankle while walking and provides different levels of sound and light feedback depending on the amount of electricity generated. Moreover, we presented the results of a questionnaire survey conducted on 172 people who experienced or observed the device, and we confirmed the effectiveness of our proposed device.

The survey results suggest that "many people are not satisfied with the amount of walking they are currently doing" and that "many people want to walk more than they currently do." Additionally, based on the interviews and impressions obtained from the observation of visitors who experienced the ankle-worn sensor sheet, it was found that the combination of "the experience of generating electricity by walking" and "the experience of changing the sound depending on the way you walk (the amount of electricity generated)," which is a novel experience for users, has to potential to encourage them to walk more. By combining these two experiences we obtained comments that supported the behavior of repeatedly walking on the spot and the motivation for that behavior.
The survey results provided the impression that the shape of the device, which was improved from the School of The Future 2020 exhibition, was generally accepted. Additionally, it was confirmed at the Tsukuba Media Art Festival 2021 that the device increased interest in walking for seven out of eight participants who did not like to walk.

The hypothesis of the Sleeve, "walking leads to power generation," refers to a function that human beings do not naturally have. This would bring "the fun of adding productivity to one's daily activities" and "the joy of being able to do more things." This hypothesis was confirmed to be correct because the experience of "walking leads to power generation" increased interest in, and promoted, walking.

Additionally, the fact that the public at the exhibitions accepted the appearance and shape of the device suggests that when devising a socially acceptable shape, the device does not necessarily have to be concealed into existing personal items. It was suggested that the device be designed to be socially acceptable even if it were created in the form of an accessory to be added to one's conventional attire-like a "shoe accessory." A comparison between related research and the Sleeve suggests that this device is suitable for daily use.

As a future prospect of this device, we would like to improve its design and playfulness. Additionally, although the Sleeve developed in this study has succeeded in making 
people interested in walking and changing their walking behavior, it has not yet been able to increase the amount of walking over a long period. Therefore, we would like to study the interaction to increase the amount of walking over a long duration and the experience of walking using this device.

As this research progresses and devices that increase the motivation to walk are developed in the future, we believe that this will lead to a healthier society. Moreover, this will support health problems, such as locomotive syndrome and dementia, which are caused by physical inactivity, and will significantly impact the society and economy.

Acknowledgements This work was supported by JSPS KAKENHI Grant Number JP 20J10876.

Open Access This article is licensed under a Creative Commons Attribution 4.0 International License, which permits use, sharing, adaptation, distribution and reproduction in any medium or format, as long as you give appropriate credit to the original author(s) and the source, provide a link to the Creative Commons licence, and indicate if changes were made. The images or other third party material in this article are included in the article's Creative Commons licence, unless indicated otherwise in a credit line to the material. If material is not included in the article's Creative Commons licence and your intended use is not permitted by statutory regulation or exceeds the permitted use, you will need to obtain permission directly from the copyright holder. To view a copy of this licence, visit http://creativecommons.org/licenses/by/4.0/.

\section{References}

Aoyagi Y, Shephard RJ (2010) Habitual physical activity and health in the elderly: the Nakanojo Study. Geriatr Gerontol Int 10(Supplement 1):S236-S243. https://doi.org/10.1111/j.1447-0594.2010. 00589.x

Baldi TL, Paolocci G, Prattichizzo D (2018) Human guidance: suggesting walking pace under manual and cognitive load. In: Prattichizzo D, Shinoda H, Tan H, Ruffaldi E, Frisoli A (eds) Lecture notes in computer science international conference on human haptic sensing and touch enabled computer applications, Italy, pp 416-427

Baldi TL, Paolocci G, Barcelli D, Prattichizzo D (2020) Wearable haptics for remote social walking. IEEE Trans Haptics 13:761-776. https://doi.org/10.1109/TOH.2020.2967049

Borkowski P, Jażdżewska-Gutta M, Szmelter-Jarosz A (2021) Lockdowned: everyday mobility changes in response to COVID-19. J Transp Geogr. https://doi.org/10.1016/j.jtrangeo.2020.102906

Bruner GC, Kumar A (2005) Explaining consumer acceptance of handheld Internet devices. J Bus Res 58:553-558. https://doi.org/10. 1016/j.jbusres.2003.08.002

Donelan JM, Li Q, Naing V et al (2008) Biomechanical energy harvesting: generating electricity during walking with minimal user effort. Science 319:807-810. https://doi.org/10.1126/science. 1149860

Fuller D, Anaraki JR, Simango B et al (2021) Predicting lying, sitting, walking and running using Apple Watch and Fitbit data. BMJ Open Sport Exerc Med 7:e001004. https://doi.org/10.1136/ bmjsem-2020-001004

Huntley D (2021) Effects of working at home during COVID-19 on sedentary behavior, use of strategies to decrease sedentary behavior, and perceived work performance. Master's degree culminating works University of Minnesota-Duluth

Iwata H (2012) Device art: a new art form in which technology and art are un-separable. Trans Hum Interface Soc 14:21-30. https://doi. org/10.11184/his.14.1_21

Karageorghis CI, Terry PC (1997) The psychophysical effects of music in sport and exercise: a review. J Sport Behav 20:54

Lee IM, Shiroma EJ, Lobelo F et al (2012) Effect of physical inactivity on major non-communicable diseases worldwide: an analysis of burden of disease and life expectancy. Lancet 380:219-229. https://doi.org/10.1016/S0140-6736(12)61031-9

Manabe Y, Kitaoka Y, Tamura H, Kunijima I (2007) Improvement of rehabilitation by foot care. J Showa Hosp 4:007-010. https://doi. org/10.11163/akanekai.4.007

Morris JN, Hardman AE (1997) Walking to health. Sports Med 23:306-332. https://doi.org/10.2165/00007256-199723050-00004

Nakamura K (2011) The concept and treatment of locomotive syndrome: its acceptance and spread in Japan. J Orthop Sci 16:489491. https://doi.org/10.1007/s00776-011-0108-5

Owen N, Humpel N, Leslie E et al (2004) Understanding environmental influences on walking; review and research agenda. Am J Prev Med 27:67-76. https://doi.org/10.1016/j.amepre.2004.03.006

Paolocci G, Baldi TL, Prattichizzo D (2018) Human rendezvous via haptic suggestion. AsiaHaptics. https://doi.org/10.1007/2F978981-13-3194-7 59

Sakai K, Hachisu T, Hashimoto Y (2018) Sole tactile display using tactile illusion by vibration on toenail. Lect Notes Electr Eng. https://doi.org/10.1007/978-981-10-4157-0_16

Schott GD (1993) Penfield's homunculus: a note on cerebral cartography. J Neurol Neurosurg Psychiatry 56:329-333. https://doi.org/ 10.1136/jnnp.56.4.329

Siegel PZ, Brackbill RM, Heath GW (1995) The epidemiology of walking for exercise: implications for promoting activity among sedentary groups. Am J Public Health 85:706-710. https://doi. org/10.2105/AJPH.85.5.706

Sugimoto M, Iwata H, Igarashi H (2019) Improvement of walking motivation by vibratory display powered by an ankle-worn generation device. Lect Notes Electr Eng. https://doi.org/10.1007/ 978-981-13-3194-7 61

Tajadura-Jiménez A, Basia M, Deroy O et al (2015) As light as your footsteps: altering walking sounds to change perceived body weight, emotional state and gait. ACM Conf Hum Factors Comput Syst 33:2943-2952. https://doi.org/10.1145/2702123.2702374

Thikey H, Grealy M, van Wijck FV et al (2012) Augmented visual feedback of movement performance to enhance walking recovery after stroke: study protocol for a pilot randomised controlled trial. Trials 13:163. https://doi.org/10.1186/1745-6215-13-163

Tison GH, Avram R, Kuhar P et al (2020) Worldwide effect of COVID19 on physical activity: a descriptive study. Ann Intern Med 173:767-770. https://doi.org/10.7326/M20-2665

Tomata Y, Zhang S, Sugiyama K et al (2017) Changes in time spent walking and the risk of incident dementia in older Japanese people: the Ohsaki Cohort 2006 Study. Age Ageing 46:857-860. https://doi.org/10.1093/ageing/afx078

Ylli K, Hoffmann D, Becker P et al (2014) Human motion energy harvesting for AAL applications. J Phys Conf Ser 557:012024. https://doi.org/10.1088/1742-6596/557/1/012024

Zhao J, You Z (2014) A shoe-embedded piezoelectric energy harvester for wearable sensors. Sensors (basel) 14:12497-12510. https://doi. org/10.3390/s 140712497

Publisher's Note Springer Nature remains neutral with regard to jurisdictional claims in published maps and institutional affiliations. 